\title{
Jean-Yves Debreuille, Lorand Gaspar
}

\section{Fabio Scotto}

\section{(2) OpenEdition}

\section{Journals}

\section{Edizione digitale}

URL: http://journals.openedition.org/studifrancesi/9036

DOI: 10.4000/studifrancesi.9036

ISSN: 2427-5856

\section{Editore}

Rosenberg \& Sellier

\section{Edizione cartacea}

Data di pubblicazione: 1 octobre 2008

Paginazione: 490

ISSN: 0039-2944

\section{Notizia bibliografica digitale}

Fabio Scotto, «Jean-Yves Debreuille, Lorand Gaspar», Studi Francesi [Online], 155 (LII | II) | 2008, online dal 30 novembre 2015, consultato il 13 janvier 2021. URL: http://journals.openedition.org/ studifrancesi/9036 ; DOI: https://doi.org/10.4000/studifrancesi.9036

Questo documento è stato generato automaticamente il 13 janvier 2021.

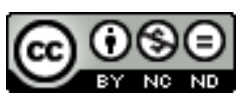

Studi Francesi è distribuita con Licenza Creative Commons Attribuzione - Non commerciale - Non opere derivate 4.0 Internazionale. 


\title{
Jean-Yves Debreuille, Lorand Gaspar
}

\author{
Fabio Scotto
}

\section{NOTIZIA}

JEAN-YVeS DEBReuiLLE, Lorand Gaspar, Paris, Seghers, 2007 («Poètes d'aujourd'hui»), pp.

259.

1 Jean-Yves Debreuille, professore all'Université Lyon-II, ci offre nella nuova serie di una Collana storica della poesia francese un pregevole studio su Lorand Gaspar (1925). Di origine ungherese, Gaspar, autentico poliglotta, nonché medico chirurgo, ha vissuto in Palestina, in Arabia, a Betlemme, Gerusalemme e Tunisi, sviluppando un'opera che molto deve al suo nomadismo esistenziale e al suo sincretismo culturale e linguistico. L'ampio saggio introduttivo di Debreuille (pp. 9-122) ne ripercorre in modo articolato l'avventura soffermandosi sulle opere principali prese in esame in ordine cronologico e muovendo da una frase emblematica di Gaspar: «Au commencement - mais au commencement il y a la fin» (Judée, p. 168), che ben dice la circolarità del tempo e il suo ancorarsi nell'àmbito umano della finitudine. L'A. individua ne l'Ouverture la matrice «éthique» (p. 9) del suo nomadismo, la cui esperienza si effettua attraverso quattro meditazioni essenziali: il deserto, il mare, la luce, l'oggetto portatore di senso (pp. 10-11). Animato da una grande sete di conoscenza, «Lorand Gaspar», afferma l'A., «n'est pas le produit de son passé, mais le passant d'installations successives qui l'ont chaque fois accru, et à partir desquelles il revisite et réinterprète ce qu'il a connu auparavant» (p. 23). E proprio questa idea di autocostruzione di sé attraverso l'opera in una continua specularità di natura e di Io che si sedimenta, come l'arida pietra arsa dal sole, attraverso le ere geologiche pare caratterizzare il percorso di scrittura di Gaspar, nella spinoziana coincidenza di res cogitans e di res extensa del «corps-esprit» (p. 110) che molto deve anche alla lezione di Montaigne e alla consistenza materico-visionaria dell'espressionismo di Michaux.

2 L'A. ben sottolinea come in questa ricerca, che si svolge in versi e in prosa, il movimento sia più importante della traccia (p. 78), in costante fedeltà al precetto 
hölderliniano di abitazione poetica del mondo (p. 81). L'approccio critico di Debreuille privilegia gli snodi fondamentali di poetica del pensiero in rapporto all'esistenza del poeta, dall'infanzia al viaggio, anche acutamente evidenziando la continuità fra il lavoro di medico e il lavoro poetico, duplice passione nata nel 1944 su un carro bestiame diretto in Germania di fronte a un uomo sbudellato, di qui il desiderio, attraverso il bisturi e la parola, di «s'occuper de tout ce qui est blessure et plaie» (p. 114). Ciò che allora fa la riuscita di una poesia non è né «le parti pris des choses» pongiano né l'artificialità del linguaggio, quanto piuttosto «un travail sur soi» (p. 121) attraverso la lingua, ovvero quello che nella sezione antologica del volume (pp. 123-251), anche corredata di testi inediti, Gaspar chiama «une clarté mûrie dans la chair/ [...] / ce que ni mots, ni musique, ni rien/ ne peuvent imaginer, ni dire -» (p. 237). 